\title{
BMJ
}

\section{Combined effects of overweight and smoking in late adolescence on subsequent mortality: nationwide cohort study}

\author{
Martin Neovius, postdoctoral fellow ${ }^{1,2}$ Johan Sundström, associate professor ${ }^{3}$ Finn Rasmussen, professor ${ }^{2}$
}

${ }^{1}$ Clinical Epidemiology Unit, Department of Medicine,

Karolinska Institute, Karolinska University Hospital, SE-171 76 Stockholm, Sweden

${ }^{2}$ Department of Public Health Sciences, Karolinska Institute, Karolinska University Hospital (Norrbacka)

${ }^{3}$ Department of Medical Sciences Uppsala University Hospital, SE-75185 Uppsala, Sweden Correspondence to: $M$ Neovius martin.neovius@ki.se

Cite this as: $B M J$ 2009;338:b496 doi:10.1136/bmj.b496

\section{ABSTRACT}

Objective To investigate the combined effects on adult mortality of overweight and smoking in late adolescence. Design Record linkage study with Cox proportional hazard ratios adjusted for muscle strength, socioeconomic position, and age.

Setting Swedish military service conscription register, cause of death register, and census data.

Participants 45920 Swedish men (mean age 18.7, SD 0.5) followed for 38 years.

Main outcome measures Body mass index (underweight (BMI <18.5), normal weight (18.5-24.9), overweight (2529.9), and obesity ( $\geq 30)$ ), muscle strength, and self reported smoking (non-smoker, light smoker (1-10 cigarettes/day), heavy smoker (>10/day)) at mandatory military conscription tests in 1969-70. All cause mortality. Results Over 1.7 million person years, 2897 men died. Compared with normal weight men (incidence rate 17/ 10000 person years, $95 \%$ confidence interval 16 to 18 ), risk of mortality was increased in overweight (hazard ratio 1.33 , 1.15 to 1.53 ; incidence rate 23,20 to 26 ) and obese men (hazard ratio $2.14,1.61$ to 2.85 ; incidence rate 38,27 to 48 ), with similar relative estimates in separate analyses of smokers and non-smokers. No increased risk was detected in underweight men (hazard ratio 0.97, 0.86 to 1.08 ; incidence rate 18,16 to 19 ), though extreme underweight (BMI <17) was associated with increased mortality (hazard ratio $1.33,1.07$ to 1.64 ; incidence rate 24,19 to 29 ). The relative excess risk due to interaction between $\mathrm{BMI}$ and smoking status was not significant in any stratum. Furthermore, all estimates of interaction were of small magnitude, except for the combination of obesity and heavy smoking (relative excess risk $1.5,-0.7$ to 3.7). Compared with non-smokers (incidence rate 14, 13 to 15), risk was increased in both light (hazard ratio 1.54, 1.41 to 1.70; incidence rate 15,14 to 16 ) and heavy smokers (hazard ratio $2.11,1.92$ to 2.31 ; incidence rate 26,24 to 27 ).

Conclusions Regardless of smoking status, overweight and obesity in late adolescence increases the risk of adult mortality. Obesity and overweight were as hazardous as heavy and light smoking, respectively, but there was no interaction between BMI and smoking status. The global obesity epidemic and smoking among adolescents remain important targets for intensified public health initiatives.

\section{INTRODUCTION}

The obesity pandemic seems to affect children and adolescents more than adults, with higher relative increases in overweight and obesity than in adults in several parts of the world. ${ }^{12}$ In middle aged adults, obesity (body mass index $(\mathrm{BMI}) \geq 30$ ) increases the risk of mortality twofold to threefold compared with people of normal weight (BMI 18.5-24.9). ${ }^{3-6}$ Whether risk of mortality is also increased in overweight adults (BMI 25-29.9) is debatable, ${ }^{6-10}$ with reports of both lower $^{67}$ and higher mortality. ${ }^{35910}$ The conflicting views mainly concern handling of possible confounding because of smoking and reverse causation (with low BMI potentially being caused by pre-existing illnesses). ${ }^{10}$ The common finding of excess mortality in underweight people might be an artefact caused by insufficient adjustment for smoking. ${ }^{7112}$ Access to data on smoking in a sufficiently large sample unaffected by pre-existing illness would circumvent such problems. Available studies of younger people, however, are limited by coarse BMI modelling (obese $v$ non-obese),${ }^{13}$ having few overweight participants, ${ }^{14}$ lacking data on important covariates such as smoking and socioeconomic position, ${ }^{15}$ or analysing women only. $^{12}$

Smoking rates in adolescents remain high, ${ }^{16}$ with a marked increase over the past decades in some countries. ${ }^{17}$ In adults in the United States, smoking was ranked as the behavioural risk factor resulting in the most excess deaths in 2000 , closely followed by diet and activity patterns, accounting for $18.1 \%$ and $16.6 \%$ of excess deaths, respectively. ${ }^{18}$ In adolescents as well as in adults, smoking and overweight or obesity are the two most important modifiable risk factors for mortality in the Western world. While smoking is already a major problem in developing countries, obesity is becoming one in all regions of the world except the very poorest. ${ }^{19}$ Despite that, the combined effects on mortality associated with these two risk factors and their interaction in late adolescence are not known.

We hypothesised that overweight and smoking in late adolescence increase the risk of mortality and that their effects are synergistic. Our secondary hypothesis was that excess risk in underweight people is accounted 
for by smoking. We investigated these hypotheses using a large nationwide cohort of men from a military conscription registry.

\section{METHODS}

\section{Sample}

The study was based on nationwide military conscription data from 49321 Swedish men born 1949-51 who performed mandatory military conscription tests in 1969-70. The background of the military conscription registry data has been presented in detail elsewhere. ${ }^{20}$ Only 2-3\% of all Swedish men were exempt from conscription at this time, in most cases because of severe handicaps or congenital disorders. The men we included accounted for $97.7 \%$ of all conscripts in 196970 , with the $2.3 \%$ remaining born before 1949 . Based on the unique personal identification number assigned to each Swedish citizen, we performed record linkage of the conscription registry and the cause of death registry. To be included in the current study, men were required to have performed their induction tests between the ages of 16 and 20 and have recorded data on measured weight and height and self reported smoking habits at conscription. The age restriction was used to keep the sample homogenous by age. Although most men in Sweden perform their conscription test the year they turn 18, some test at other ages.

\section{Baseline examinations}

We used WHO defined categories of body mass index (BMI, weight $(\mathrm{kg}) /\left(\right.$ height $\left.(\mathrm{m})^{2}\right)$ : underweight $(<18.5)$, normal weight (18.5-24.9), overweight (25-29.9), and obese $(\geq 30){ }^{21}$

The conscription registry contains a small number of extreme values on weight, height, and BMI, which might be true values or represent errors in measurement or data entry. To minimise errors of random misclassifications, we applied exclusion limits for height $(\leq 150$ or $\geq 210 \mathrm{~cm})$, weight $(\leq 40$ or $\geq 150 \mathrm{~kg}$ ), and BMI $(\leq 15$ or $\geq 60)$. We categorised smoking status into three levels (non-smoker, 1-10 (light smoker), >10 cigarettes/day (heavy smoker)) using a questionnaire. Covariates considered were muscle strength (leg extension, arm flexion, and hand grip), household socioeconomic status, and age at testing. We retrieved parental socioeconomic status (white collar, blue collar, self employed, other) in 1970 from the population and housing census in 1970 . We used the highest of the maternal and paternal socioeconomic status as household socioeconomic status. If both were missing, we used the registered socioeconomic status of the military conscript

\section{Follow-up and outcomes}

Mortality data were retrieved from the national cause of death registry until 1 September 2007. Participants

Table 1|Baseline characteristics of study population* according to BMI†. Figures are numbers (percentage) or means (SD) for continuous variables

\begin{tabular}{|c|c|c|c|c|c|}
\hline & Underweight & Normal weight & Overweight & Obesity & Total \\
\hline No (\%) in group & $6325(13.8)$ & $36605(79.7)$ & $2623(5.7)$ & $367(0.8)$ & $45920(100)$ \\
\hline \multicolumn{6}{|l|}{ Anthropometry: } \\
\hline Height $(\mathrm{cm})$ & $178.6(6.5)$ & $178.1(6.3)$ & $177.7(6.4)$ & $177.2(6.7)$ & $178.1(6.3)$ \\
\hline Weight (kg) & $56.3(4.6)$ & $66.7(6.8)$ & $84.1(7.4)$ & $101.1(10.0)$ & $66.6(9.2)$ \\
\hline $\mathrm{BMI}$ & $17.6(0.7)$ & $21.0(1.6)$ & $26.6(1.3)$ & $32.2(2.0)$ & $21.0(2.6)$ \\
\hline \multicolumn{6}{|l|}{ Smoking: } \\
\hline Non-smoker & $2325(37)$ & $15430(42)$ & $1107(42)$ & $145(40)$ & $19007(41)$ \\
\hline 1-10/day & $2286(36)$ & $11771(32)$ & $711(27)$ & $84(23)$ & $14852(32)$ \\
\hline >10/day & $1714(27)$ & $9404(26)$ & $805(31)$ & $138(38)$ & $12061(26)$ \\
\hline \multicolumn{6}{|l|}{ Covariates: } \\
\hline Age (years) & $18.7(0.5)$ & $18.7(0.5)$ & $18.7(0.5)$ & $18.7(0.5)$ & $18.7(0.5)$ \\
\hline Hand grip $\ddagger$ & $549(85)$ & $613(96)$ & $648(107)$ & $653(112)$ & $607(98)$ \\
\hline Arm flexion $\ddagger$ & $311(57)$ & $375(76)$ & $424(88)$ & $438(89)$ & $369(79)$ \\
\hline Leg extension $\ddagger$ & $459(83)$ & $542(99)$ & $601(110)$ & $623(122)$ & $535(103)$ \\
\hline \multicolumn{6}{|l|}{ Socioeconomic status: } \\
\hline White collar & $2953(47)$ & $15549(42)$ & $913(35)$ & $99(27)$ & $19514(43)$ \\
\hline Blue collar & $2308(37)$ & $13723(38)$ & $1198(46)$ & $198(54)$ & $17427(38)$ \\
\hline Self employed & 842 (13) & 6229 (17) & $448(17)$ & 63 (17) & $7582(17)$ \\
\hline Other & $220(3)$ & $1088(3)$ & $64(2)$ & $7(2)$ & 1379 (3) \\
\hline \multicolumn{6}{|l|}{ Incidence of death: } \\
\hline Deaths & 400 & 2231 & 217 & 49 & 2897 \\
\hline Person years & 228529 & 1321988 & 94915 & 13052 & 1658485 \\
\hline $\begin{array}{l}\text { Deaths/10 } 000 \text { person years } \\
(95 \% \mathrm{Cl})\end{array}$ & $\begin{array}{c}17.5 \\
(15.8 \text { to } 19.2)\end{array}$ & $\begin{array}{c}16.9 \\
(16.2 \text { to } 17.6)\end{array}$ & $\begin{array}{c}22.9 \\
(19.8 \text { to } 25.9)\end{array}$ & $\begin{array}{c}37.5 \\
\text { (27.0 to } 48.1)\end{array}$ & $\begin{array}{c}17.5 \\
(16.8 \text { to } 18.1)\end{array}$ \\
\hline
\end{tabular}

* Data missing on leg strength for 8 , arm strength for 17 , and socioeconomic status for 18.

†Body mass index $\left(\mathrm{kg} / \mathrm{m}^{2}\right)$ : underweight $<18.5$, normal weight 18.5-24.9, overweight $25-29.9$, obese $\geq 30$. $\ddagger$ Measured in newtons. 
Table 2 | Deaths in smokers and non-smokers according to BMI* category

\begin{tabular}{|c|c|c|c|c|c|}
\hline & $\begin{array}{c}\text { Non-smoker }(\mathrm{n}=18 \\
990)\end{array}$ & $\begin{array}{c}\text { Smoker } \\
(\mathrm{n}=26894)\end{array}$ & $\begin{array}{l}\text { Light smoker (1-10/day) } \\
\qquad(\mathrm{n}=14846)\end{array}$ & $\begin{array}{l}\text { Heavy smoker ( }(10 / \text { day }) \\
(n=12048)\end{array}$ & Total $(n=45884)$ \\
\hline Person years $\dagger$ & 689628 & 968138 & 536243 & 431895 & 1657766 \\
\hline Deaths (total) $\dagger$ & 806 & 2072 & 976 & 1096 & 2878 \\
\hline \multicolumn{6}{|l|}{ BMI category: } \\
\hline Underweight & 96 & 301 & 138 & 163 & 397 \\
\hline Normal & 634 & 1582 & 760 & 822 & 2216 \\
\hline Overweight & 63 & 153 & 68 & 85 & 216 \\
\hline Obese & 13 & 36 & 10 & 26 & 49 \\
\hline
\end{tabular}

*Body mass index $\left(\mathrm{kg} / \mathrm{m}^{2}\right)$ : underweight $<18.5$, normal weight 18.5-24.9, overweight 25-29.9, obese $\geq 30$.

†Deaths and person years are for participants with data on all covariates used in Cox regressions in tables 4 and 5 . Therefore numbers do not equal those shown in table 1.

who did not die during follow-up were censored at that time or at time of emigration.

\section{Statistical analysis}

Data were analysed with SAS (version 9, SAS Institute, Cary, NC) and Stata (version 10.0, College Station, TX). Unadjusted incidence rates (deaths/10000 person years) and Kaplan-Meier failure functions were used to present the absolute risk of death. A Cox proportional hazards model was used to model time to

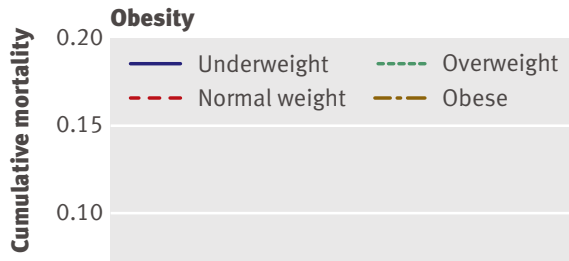

0.05

No at risk

$\begin{array}{lcccccccc}\text { Underweight } & 6326 & 6270 & 6216 & 6155 & 6094 & 6001 & 5888 & 5753 \\ \text { Normal weight } & 36635 & 36339 & 35984 & 35587 & 35213 & 34730 & 34090 & 33350 \\ \text { Overweight } & 2591 & 2576 & 2553 & 2531 & 2509 & 2468 & 2410 & 2335 \\ \text { Obese } & 367 & 364 & 359 & 353 & 350 & 343 & 334 & 318\end{array}$

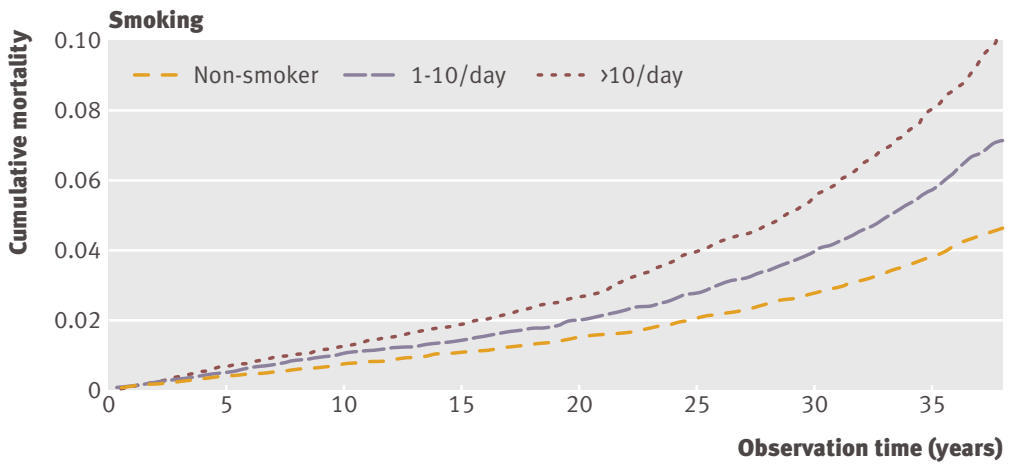

No at risk

$\begin{array}{lllllllll}\text { Non-smoker } & 19007 & 18871 & 18698 & 18492 & 18328 & 18118 & 17839 & 17537 \\ \text { 1-10/day } & 14852 & 14742 & 14589 & 14434 & 14283 & 14083 & 13817 & 13499 \\ \text { >10/day } & 12060 & 11936 & 11825 & 11700 & 11555 & 11341 & 11066 & 10720\end{array}$

Fig 1| Cumulative mortality according to obesity status (underweight (BMI <18.5), normal weight (18.5-24.9), overweight (25-29.9), obesity $(\geq 30))$ and smoking status over 38 years of observation event for estimation of relative risks of death, unadjusted and adjusted for potential confounding variables. ${ }^{22}$ Reference categories were normal BMI and non-smoker.

Initially we fitted unadjusted models for BMI, smoking, and both variables combined. These three models were thereafter adjusted for muscle strength, socioeconomic status, and age at testing. Multivariable adjusted BMI models were then repeated in four categories of smoking (non-smokers, smokers, light smokers, and heavy smokers) and smoking models were repeated in four categories of BMI (underweight, normal weight, overweight, and obesity).

In our secondary analyses, we fitted an additional model with the underweight category split into moderate (BMI 17-18.4) and extreme underweight $(\mathrm{BMI}<17)$ to detect potential differences. Also, for comparison with previous work on adolescent women, ${ }^{12}$ we fitted a model with BMI 18.5-21.9 as reference to investigate whether small increases in BMI (22.0-24.9) were associated with excess risk.

We investigated biological interaction, as defined by Rothman, ${ }^{23}$ between BMI and smoking status by calculating the relative excess risk because of the interaction (RERI) by using the methods outlined by Andersson et al. ${ }^{24}$ In this analysis we calculated the separate contributions to the relative risk of death from the BMI category, smoking category, and the interaction between the two. In the absence of a biological interaction between BMI and smoking status, the relative excess risk will be 0 .

Using bootstrap estimated $95 \%$ confidence intervals obtained by re-sampling 45000 individuals 1000 times, we compared the hazard ratios for heavy smoking ( $v$ non-smoking) and obesity ( $v$ normal weight) and those for light smoking ( $v$ non-smoking) and overweight ( $v$ normal weight) in the fully adjusted model.

Few data were missing, and Cox regressions were based on complete case analyses.

\section{RESULTS}

Of 50398 participants in the database, 889 had no recorded data on smoking, while 951 had weight, height, or BMI outside the acceptable limits. Of the 48691 remaining participants, we excluded 2771 as 


\begin{tabular}{|c|c|c|c|c|c|}
\hline & $\begin{array}{l}\text { Underweight } \\
(\mathrm{n}=6320)\end{array}$ & $\begin{array}{c}\text { Normal weight }(\mathrm{n}=36 \\
575)\end{array}$ & $\begin{array}{l}\text { Overweight } \\
(n=2622)\end{array}$ & Obese $(n=367)$ & Total $(n=45884)$ \\
\hline Person years $†$ & 228431 & 1321398 & 94885 & 13052 & 1657766 \\
\hline Deaths (total) $\dagger$ & 397 & 2216 & 216 & 49 & 2878 \\
\hline \multicolumn{6}{|l|}{ Smoking category: } \\
\hline Non-smoker & 96 & 634 & 63 & 13 & 806 \\
\hline Light smoker (1-10/day) & 138 & 760 & 68 & 10 & 976 \\
\hline Heavy smoker (>10/day) & 163 & 822 & 85 & 26 & 1096 \\
\hline
\end{tabular}

*Body mass index $\left(\mathrm{kg} / \mathrm{m}^{2}\right)$ : underweight $<18.5$, normal weight 18.5-24.9, overweight 25-29.9, obese $\geq 30$.

†Deaths and person years are for participants with data on all covariates used in Cox regressions in tables 4 and 5 . Therefore numbers do not equal those shown in table 1.

they were aged $>20$ at the conscription test, leaving a final 45920 participants for analysis. Table 1 shows details of the participants. Tables 2 and 3 show deaths according to BMI category and smoking.

\section{Unadjusted survival analyses}

During 1.7 million person years (median 38 years) of follow-up, 2897 men died and 1806 emigrated. Figure 1 shows the cumulative mortality during follow-up according to obesity and smoking status.

The incidence of death was the lowest in normal weight men and highest in obese men (table 1, fig 1). In unadjusted models with normal weight participants as reference, the risk of mortality was significantly higher for overweight (hazard ratio 1.35, 95\% confidence interval 1.17 to $1.55, \mathrm{P}<0.001)$ and obese $(2.25,1.70$ to $2.98, \mathrm{P}<0.001)$ men but not underweight men (1.04, 0.93 to $1.15, \mathrm{P}=0.51)$. With non-smokers as the reference category, there was a gradually increasing risk from men who smoked 1-10 cigarettes/day (1.55, 1.41 to $1.70, \mathrm{P}<0.001)$ to $>10$ cigarettes/day $(2.18,1.99$ to $2.39, \mathrm{P}<0.001)$ in unadjusted analyses. The absolute risks of death were 14.2 (13.3 to 15.1 ), 15.2 (14.2 to 16.2 ), and 25.5 (24.0 to 27.0) per 10000 person years in non-smokers, light smokers, and heavy smokers, respectively.

\section{Multivariable adjusted survival analyses}

The significantly increased risks in overweight and obese men remained in our multivariable adjusted analyses of obesity status as a predictor for mortality, with adjustment for smoking, muscle strength, socioeconomic status, and age (table 4). The hazard ratios changed little when we included or excluded smoking as a covariate or analysed smokers and non-smokers separately. When we further stratified participants into light and heavy smokers, the direction of the point estimates for the BMI categories remained the same, although the confidence intervals widened. The hazard ratio among underweight men did not differ significantly from that in normal weight men in any category.

Similarly, the hazard ratios for smoking remained unchanged before and after adjustment for BMI status (table 5). Although the point estimates differed in magnitude across BMI categories, all were in the same direction and all but one were significant.

\section{Subcategories of BMI and risk of mortality}

Although being underweight $(\mathrm{BMI}<18.5)$ was not associated with increased risk compared with normal weight, further stratification showed that extremely underweight men $(\mathrm{BMI}<17)$ had a significantly increased risk of about the same magnitude (adjusted hazard ratio $1.33,1.07$ to $1.64, \mathrm{P}=0.009$; unadjusted $1.47,1.20$ to $1.80, \mathrm{P}<0.001)$ as that in overweight men compared with the normal weight reference category.

Further stratification of the normal weight group also showed significant graded increases from a BMI of 18.5-21.9 (reference) to BMI 22-24.9 (1.15, 1.05 to 1.27, $\mathrm{P}=0.004)$.

\section{Combined effects of smoking and BMI}

Figure 2 shows the combined effects of smoking and obesity status. The unadjusted mortality rate was similar for obese non-smokers and normal weight heavy smokers. After adjustment, the difference in

Table 4 | Relative risks of premature death estimated by Cox regression analysis* (with 95\% confidence intervals) according to categories of BMI† and smoking

\begin{tabular}{|c|c|c|c|c|c|c|}
\hline \multirow[b]{2}{*}{ BMI } & \multicolumn{2}{|c|}{ Total $(n=45884)$} & \multicolumn{4}{|c|}{ Smoking status } \\
\hline & Base model & $\begin{array}{l}\text { Adjusted also for } \\
\text { smoking }\end{array}$ & $\begin{array}{c}\text { Non-smokers } \\
(n=18990)\end{array}$ & Smokers $(n=26894)$ & $\begin{array}{l}\text { Light }(1-10 / \text { day }) \\
\quad(n=14846)\end{array}$ & $\begin{array}{l}\text { Heavy }(>10 / \text { day }) \\
\quad(n=12048)\end{array}$ \\
\hline Underweight & $\begin{array}{c}1.00(0.89 \text { to } 1.12), \\
P=0.99\end{array}$ & $\begin{array}{c}0.97 \text { (0.86 to } 1.08), \\
P=0.56\end{array}$ & $\begin{array}{c}0.94(0.75 \text { to } 1.18) \\
P=0.62\end{array}$ & $\begin{array}{c}0.97(0.85 \text { to } 1.11) \\
P=0.69\end{array}$ & $\begin{array}{c}0.91(0.75 \text { to } 1.10), \\
P=0.32\end{array}$ & $\begin{array}{c}1.05(0.88 \text { to } 1.25), \\
P=0.61\end{array}$ \\
\hline Normal weight & 1 & 1 & 1 & 1 & 1 & 1 \\
\hline Overweight & $\begin{array}{c}1.34 \text { (1.16 to } 1.55), \\
\text { P }<0.001\end{array}$ & $\begin{array}{c}1.33 \text { (1.15 to } 1.53), \\
\text { P }<0.001\end{array}$ & $\begin{array}{c}1.37(1.05 \text { to } 1.79), \\
P=0.02\end{array}$ & $\begin{array}{c}1.35 \text { (1.14 to } 1.60), \\
\text { P } 0.001\end{array}$ & $\begin{array}{c}\text { 1.44, }(1.11 \text { to } 1.86), \\
P=0.006\end{array}$ & $\begin{array}{c}1.23(0.98 \text { to } 1.54), \\
P=0.08\end{array}$ \\
\hline Obesity & $\begin{array}{c}2.22 \text { (1.66 to 2.95), } \\
\text { P<0.001 }\end{array}$ & $\begin{array}{c}2.14 \text { (1.61 to } 2.85), \\
P<0.001\end{array}$ & $\begin{array}{c}2.16(1.24 \text { to } 3.76), \\
P=0.007\end{array}$ & $\begin{array}{c}2.23 \text { (1.60 to } 3.12), \\
P<0.001\end{array}$ & $\begin{array}{c}1.83(0.98 \text { to } 3.42), \\
P=0.06\end{array}$ & $\begin{array}{c}2.27 \text { (1.53 to 3.38), } \\
\text { P }<0.001\end{array}$ \\
\hline
\end{tabular}


Table $5 \mid$ Relative risks of premature death estimated by Cox regression analysis* (with $95 \%$ confidence intervals) according to categories of smoking and BMI $\dagger$

\begin{tabular}{|c|c|c|c|c|c|c|}
\hline \multirow[b]{2}{*}{ Smoking } & \multicolumn{2}{|c|}{ Total $(n=45884)$} & \multicolumn{4}{|c|}{ Obesity status } \\
\hline & Base model & Adjusted also for BMI & Underweight $(n=6320)$ & $\begin{array}{c}\text { Normal weight }(n=36 \\
575)\end{array}$ & Overweight $(n=2622)$ & Obese $(n=367)$ \\
\hline Non-smokers & 1 & 1 & 1 & 1 & 1 & 1 \\
\hline Light (1-10/day) & $\begin{array}{c}1.53 \text { (1.40 to } 1.68), \\
\text { P } 0.001\end{array}$ & $\begin{array}{c}1.54 \text { (1.41 to } 1.70), \\
\text { P } 0.001\end{array}$ & $\begin{array}{c}1.47 \text { (1.13 to } 1.91), \\
P=0.004\end{array}$ & $\begin{array}{c}1.56 \text { (1.40 to } 1.73), \\
\text { P } 0.001\end{array}$ & $\begin{array}{c}1.66 \text { (1.17 to } 2.35), \\
P=0.005\end{array}$ & $\begin{array}{c}1.36(0.60 \text { to } 3.11), \\
P=0.46\end{array}$ \\
\hline Heavy (>10/day) & $\begin{array}{c}2.11 \text { (1.93 to } 2.32 \text { ), } \\
\text { P }<0.001\end{array}$ & $\begin{array}{c}2.11 \text { (1.92 to } 2.31) \\
\text { P }<0.001\end{array}$ & $\begin{array}{c}2.36 \text { (1.83 to } 3.04) \\
\text { P }<0.001\end{array}$ & $\begin{array}{c}2.09 \text { (1.89 to } 2.32) \\
\text { P }<0.001\end{array}$ & $\begin{array}{c}1.85 \text { (1.33 to } 2.57) \\
\text { P }<0.001\end{array}$ & $\begin{array}{c}2.17(1.11 \text { to } 4.23), \\
P=0.02\end{array}$ \\
\hline
\end{tabular}

${ }^{*}$ All models adjusted for muscular strength, socioeconomic status, and age.

$\dagger$ †ody mass index $\left(\mathrm{kg} / \mathrm{m}^{2}\right)$ : underweight $<18.5$, normal weight 18.5-24.9, overweight $25-29.9$, obese $\geq 30$.

hazard ratios between heavy smoking ( $v$ non-smoking) and obesity ( $v$ normal weight) was -0.02 (bootstrap obtained $95 \%$ confidence interval -0.69 to 0.64 , $\mathrm{P}=0.96$ ). Similarly, overweight and light smoking were associated with similar increases in risk of mortality with a difference in hazard ratios between light smoking ( $v$ non-smoking) and overweight $(v$ normal weight) of $0.22(-0.04$ to $0.45, \mathrm{P}=0.08)$.

Compared with normal weight men who did not smoke, the hazard ratios for groups defined by BMI and smoking status were large ( 1.31 to 4.74 ; table 6 ) and highly significant $(\mathrm{P}<0.001$ to $\mathrm{P}=0.02)$ for all but two groups: moderately underweight non-smokers $(0.92$, 0.72 to $1.17, \mathrm{P}=0.48$ ) and extremely underweight nonsmokers $(1.24,0.81$ to 1.91$)$. Overweight and obese heavy smokers, respectively, had hazard ratios $>2$ $(2.55,2.03$ to $3.20, \mathrm{P}<0.001)$ and close to five times higher $(4.74,3.20$ to $7.03, \mathrm{P}<0.001)$ than normal weight non-smokers.

Figure 3 shows the separate contributions to the relative risk of death from BMI and smoking status, as well as the interaction between the two. The relative excess risk due to interaction between smoking and BMI status did not reach significance in any category of BMI. Furthermore, the point estimates were generally small: the interaction between mild smoking and either underweight, overweight, or obesity resulted in contributions to the relative risk of -0.1 to 0.4 , and heavy smoking with underweight or overweight increased the relative risk with 0.1 over and above what would be expected from the two risk factors without any

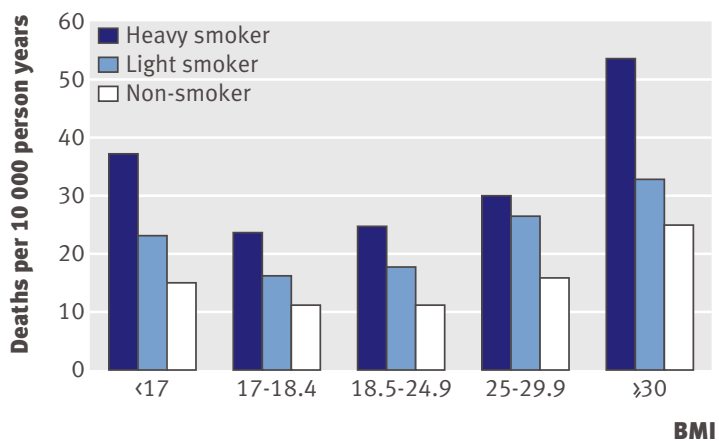

Fig 2 | Unadjusted incidence rates for mortality showing combined effects of BMI and smoking ( $n=45920)$. Light smoker=1-10 cigarettes/day; heavy smoker >10 cigarettes/ day interaction effect. Though not significant, however, the combined effect of obesity and heavy smoking was large, with a relative excess risk due to interaction of 1.5 .

\section{DISCUSSION}

In this follow-up study of men aged 16-19 at baseline we found a J shaped relation between BMI and premature death in non-smokers as well as in light and heavy smokers. Compared with men of normal weight, we found excess risks for overweight and obese men, irrespective of smoking status. Although the combination of heavy smoking and obesity was associated with a large increase in risk, we found no significant interaction between BMI and smoking status. The risks of mortality for underweight, overweight, and obesity were of similar magnitude in models that analysed smokers and non-smokers separately, as well as in models with multivariate adjustment. The excess risk conferred by obesity in late adolescence was of similar magnitude as smoking $>10$ cigarettes/day, and

Table 6 | Adjusted $^{\star}$ hazard ratios for mortality according to $\mathrm{BMI}$ and smoking†

\begin{tabular}{|c|c|c|}
\hline BMI and smoking & Hazard ratio $(95 \% \mathrm{Cl})$ & P value \\
\hline \multicolumn{3}{|c|}{ Extreme underweight (BMK17) } \\
\hline Non-smoker & $1.24(0.81$ to 1.91$)$ & 0.32 \\
\hline Light smoker & 1.80 (1.25 to 2.59$)$ & 0.002 \\
\hline Heavy smoker & 3.09 (2.26 to 4.23$)$ & $<0.001$ \\
\hline \multicolumn{3}{|c|}{ Moderate underweight (BMI 17-18.4) } \\
\hline Non-smoker & $0.92(0.72$ to 1.17$)$ & 0.48 \\
\hline Light smoker & 1.31 (1.06 to 1.61$)$ & 0.01 \\
\hline Heavy smoker & 2.00 (1.64 to 2.44$)$ & $<0.001$ \\
\hline \multicolumn{3}{|c|}{ Normal weight (BMI 18.5-24.9) } \\
\hline Non-smoker & 1.00 & \\
\hline Light smoker & 1.56 (1.40 to 1.73$)$ & $<0.001$ \\
\hline Heavy smoker & 2.10 (1.89 to 2.33$)$ & $<0.001$ \\
\hline \multicolumn{3}{|c|}{ Overweight (BMI 25-29.9) } \\
\hline Non-smoker & 1.36 (1.05 to 1.77$)$ & 0.02 \\
\hline Light smoker & 2.33 (1.81 to 3.00$)$ & $<0.001$ \\
\hline Heavy smoker & $2.55(2.03$ to 3.20$)$ & $<0.001$ \\
\hline \multicolumn{3}{|l|}{ Obesity (BMI $\geq 30$ ) } \\
\hline Non-smoker & 2.14 (1.24 to 3.72$)$ & 0.01 \\
\hline Light smoker & 2.88 (1.54 to 5.39$)$ & 0.00 \\
\hline Heavy smoker & 4.74 (3.20 to 7.03$)$ & $<0.001$ \\
\hline
\end{tabular}

*Adjusted for muscle strength, socioeconomic status, and age. †Light smoking 1-10 cigarettes/day, heavy smoking $>10$ cigarettes/day. 


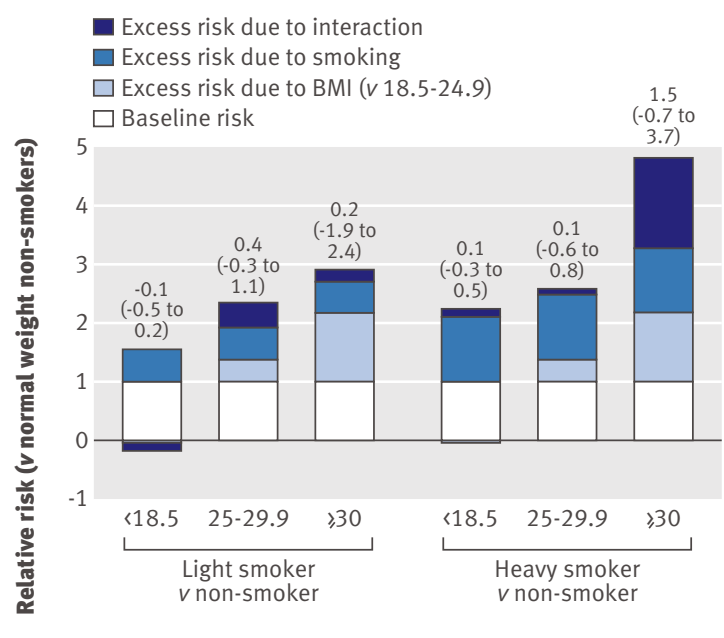

Fig $3 \mid$ Relative risks of death with separate contributions from the exposure categories BMI status, smoking status, and their interaction, with point estimates and $95 \%$ confidence intervals for relative excess risk due to interaction (RERI) between BMI and smoking status. Models adjusted for muscle strength, socioeconomic status, and age

the risk associated with overweight was similar to that of 1-10/day.

\section{Absence of interaction between BMI and smoking}

Most previous studies on the relation between BMI in late adolescence and mortality have not had access to data on smoking. ${ }^{131525}$ In one study of US female nurses based on recalled BMI at age 18, van Dam et al found a similar relative risk of mortality across categories of BMI in non-smokers as in the sample as a whole, describing a linear rather than a J shaped association. ${ }^{12}$ This might support the notion of an absence of interaction. Our findings in Swedish men largely agree with that study. We also explicitly investigated potential synergistic effects between smoking and categories of BMI and found no significant interaction between light or heavy smoking with either underweight or overweight. The combination of obesity and heavy smoking was associated with a seemingly large relative excess risk because of interaction, though it did not reach significance.

\section{Overweight and mortality}

The finding of a significantly increased risk of death with obesity agrees with several previous studies in late adolescence. ${ }^{12}{ }^{13}$ Regarding overweight, the evidence is more mixed for older adults, ${ }^{3-7}$ while few previous studies have investigated this issue in late adolescence for men. For US women, data based on recalled BMI at age 18 have previously shown increased relative risks for all cause mortality in overweight women compared with women with BMI 18.5-21.9. ${ }^{12}$ Significantly increased risks of death for Norwegian men and women aged 14-19 with a BMI between the 85th and 94th centile have also been reported, but no data were available on any potential confounders. ${ }^{15}$ Our findings constitute an extension of these previous findings. The current study and the two previous ${ }^{12} 15$ studies indicate adolescent overweight to be a serious health concern, in contrast with some reports from adult samples. ${ }^{6-8}$ The higher hazard ratios found in adolescent women might partly be caused by the different choice of reference category (18.5-21.9 v 18.5-24.9), which probably inflated the relative risks in the study by van Dam et al. ${ }^{12}$ When we re-analysed our data with BMI 18.5-21.9 as reference category, the hazard ratios for overweight increased to 1.41 (1.22 to 1.63), and we also found significantly increased risks in the upper range of the normal weight category (BMI 22.0-24.9; 1.15, 1.05 to $1.27, \mathrm{P}=0.004$ ).

\section{Underweight and mortality}

Underweight has also been found to be significantly associated with small increases in relative risk of mortality in some ${ }^{357}$ but not all previous studies. ${ }^{1112}$ We found no significant increase in risk in underweight men. A potential contributing factor to this might be that our study was less likely to be affected by reverse causality - that is, that a low BMI is caused by (rather than the cause of) ill health-than studies on older adults. Although authors often try to adjust for preexisting illness by excluding deaths in the early years of follow-up, this eliminates only those participants progressing quite rapidly to death. As we investigated 18 year olds, the baseline risk of pre-existing illness was probably much lower than among people aged 30, 40, and 50. Our finding also agrees with that of van Dam et al in adolescent women, based on recalled BMI. ${ }^{12}$ When we further stratified the underweight group, however, we found a significantly increased risk of death, similar to that seen in overweight, for men with a $\mathrm{BMI}<17$. This indicates that, at least in this age group, there might be a relevant threshold somewhere within the underweight category.

\section{Biological mechanisms}

Overweight and obesity are both associated with insulin resistance, higher blood pressure, and adverse blood lipid profiles, providing a biological basis for our findings. These are likely to result in a greater incidence of type 2 diabetes and cardiovascular morbidity ${ }^{26}$ and have also been linked to several types of cancer. ${ }^{27}$ The biological basis for the increased risk in the extremely underweight is less clear but might relate to greater susceptibility to infections and generally reduced ability to withstand or cope with illnesses.

Neither light nor heavy concurrent smoking synergistically exacerbated the risks associated with underweight or overweight. Whether the combination of heavy smoking and obesity has synergistic effects will require further study as the point estimate in this study was large but did not reach statistical significance.

\section{Public health impact}

In Sweden, overweight has tripled and obesity quintupled in adolescent men since the baseline measurements in this study, ${ }^{28}$ while smoking and underweight have halved. ${ }^{2930}$ Internationally, marked 


\section{WHAT IS ALREADY KNOWN ON THIS TOPIC}

Smoking and obesity are two of the most important behavioural risk factors for premature death in the West

Whether overweight (but not obesity) and underweight in late adolescence are associated with increased risk of premature death, and whether smoking and BMI status have synergistic effects on risk of premature death in men is not known

\section{WHAT THIS STUDY ADDS}

In late adolescence, overweight was as hazardous as smoking 1-10 cigarettes a day, while obesity was as hazardous as smoking $>10$ cigarettes a day

While the underweight group as a whole did not have any excess risk of premature death compared with normal weight men, having a BMI $<17$ was associated with a similar risk increase as overweight

No significant synergistic effects of smoking and BMI status on risk of premature death were detected, although the combination of heavy smoking and obesity was associated with a large excess risk increases over the past decades have been observed in overweight and obesity ${ }^{19}$ and also in smoking in adolescence in some countries. ${ }^{17}$ Although there was little evidence of synergistic effects, except for combined heavy smoking and obesity, compared with normal weight non-smokers the risk of mortality was more than doubled for overweight light smokers, tripled for obese light smokers, and close to quintupled for obese heavy smokers. In addition, although moderate underweight at this age did not seem to confer any increased risk of mortality, extreme underweight did even after adjustment for smoking. This indicates that the relation between BMI and mortality is not linear in adolescent men, as has been suggested for adolescent women ${ }^{12}$ and adults. ${ }^{411}$ Hence it might be important to search for explanations other than smoking for the increased mortality in this subgroup.

\section{Strengths and limitations}

Our study was representative of adolescent men and had a long follow-up, measured instead of self reported height and weight, and data on smoking habits, muscle strength, and socioeconomic status. With military conscription being mandatory and participation enforced by law in the period investigated, included participants constitute close to the entire Swedish male population. Self reported BMI is known to be affected by under-reporting, which increases with increasing $\mathrm{BMI},{ }^{31-34}$ but as trained personnel measured height and weight in this study, the risks of measurement errors were small and further reduced by the exclusion limits we applied.

There were, however, several limitations. Firstly, we had no data on women as military conscription was mandatory only for men in Sweden. US data on recalled BMI at age 18 in women, however, strongly suggest that the associations also hold for women. ${ }^{12}$ Secondly, although BMI is a widely used proxy for fatness, it takes neither the muscle $v$ fat mass relation nor the distribution of fatness into account. Some degree of misclassification is therefore inevitable. The access to data on muscle strength at least partly mitigated this problem, although more direct measures of adiposity would have been preferable, and measures of fat distribution helpful. ${ }^{35}$ Thirdly, we cannot exclude effects of residual confounding caused by unmeasured or imperfectly measured confounders. Finally, the risk of mortality might also be related to changes in weight and smoking during follow-up, for which we had no data. Regarding weight change from 18 years to middle age, van Dam et al did not find any substantial increases in risk from $\geq 15 v<4 \mathrm{~kg}$ change in weight in their study on women (hazard ratio $1.05,0.84$ to 1.31 ). The impact of potential changes in smoking is less clear, but a greater rate of smoking cessation than initiation might have resulted in underestimation of the risks of smoking.

\section{Summary and conclusion}

In summary, we found that overweight and obesity in late adolescence is associated with premature death, regardless of smoking status. Obesity and overweight were as hazardous as heavy and light smoking, respectively, and there was no interaction between smoking and obesity status. The findings indicate that from a mortality perspective targets for young men should be within the non-smoking, normal weight range, and that overweight, obesity, and smoking among adolescents might be good targets for intensified public health initiatives.

Contributors: MN conceived the hypothesis, conducted the statistical analyses, and wrote the first draft of the manuscript. JS and FR provided critical input at all stages and critically reviewed and contributed to the final draft. All authors are guarantors.

Funding: MN was funded by Arbetsmarknadens Forsakrings-och Aktiebolag (AFA) and JS by the Swedish Heart-Lung Foundation and the Swedish Research Council (2007-5942). The funding sources did not read or comment on any version of the manuscript, nor influence the analyses in any way.

Competing interests: None declared.

Ethical approval: The study was approved by the ethics committee at the Karolinska Institute, Stockholm, Sweden.

1 Popkin BM, Conde W, Hou N, Monteiro C. Is there a lag globally in overweight trends for children compared with adults? Obesity (Silver Spring) 2006;14:1846-53.

2 Ogden CL, Carroll MD, Curtin LR, McDowell MA, Tabak CJ, Flegal KM. Prevalence of overweight and obesity in the United States, 19992004. JAMA 2006;295:1549-55.

3 Adams KF, Schatzkin A, Harris TB, Kipnis V, Mouw T, Ballard-Barbash R, et al. Overweight, obesity, and mortality in a large prospective cohort of persons 50 to 71 years old. N Engl J Med 2006;355:763-78.

4 Ajani UA, Lotufo PA, Gaziano JM, Lee IM, Spelsberg A, Buring JE, et al. Body mass index and mortality among US male physicians. Ann Epidemiol 2004;14:731-9.

5 Jee SH, Sull JW, Park J, Lee SY, Ohrr H, GuallarE, et al. Body-mass index and mortality in Korean men and women. N Engl J Med 2006;355:779-87.

6 McGee DL. Body mass index and mortality: a meta-analysis based on person-level data from twenty-six observational studies. Ann Epidemiol 2005;15:87-97.

7 Flegal KM, Graubard BI, Williamson DF, Gail MH. Excess deaths associated with underweight, overweight, and obesity. JAMA 2005;293:1861-7.

8 Flegal KM, Graubard BI, Williamson DF, Gail MH. Cause-specific excess deaths associated with underweight, overweight, and obesity. IAMA 2007;298:2028-37.

9 Strickler HD, Hall C, Wylie-Rosett J, Rohan T. Underweight, overweight, obesity, and excess deaths. JAMA 2005;294:551-2.

10 Willett WC, Hu FB, Colditz GA, Manson JE. Underweight, overweight, obesity, and excess deaths. JAMA 2005;294:552-3. 
11 Hu FB, Willett WC, Li T, Stampfer MJ, Colditz GA, Manson JE. Adiposity as compared with physical activity in predicting mortality among women. N EnglJ Med 2004;351:2694-703.

12 Van Dam RM, Willett WC, Manson JE, Hu FB. The relationship between overweight in adolescence and premature death in women. Ann Intern Med 2006;145:91-7.

13 Sonne-Holm S, Sorensen TI, Christensen U. Risk of early death in extremely overweight young men. BMJ 1983;287:795-7.

14 Hoffmans MD, Kromhout D, de Lezenne Coulander C. The impact of body mass index of 78,612 18-year old Dutch men on 32-year mortality from all causes. J Clin Epidemiol 1988;41:749-56.

15 Engeland A, Bjorge T, Sogaard AJ, Tverdal A. Body mass index in adolescence in relation to total mortality: 32-year follow-up of 227,000 Norwegian boys and girls. Am J Epidemiol 2003;157:517-23.

16 Warren CW, Jones NR, Peruga A, Chauvin J, Baptiste JP, Costa de Silva V, et al. Global youth tobacco surveillance, 2000-2007. MMWR Surveill Summ 2008;57:1-28.

17 Hublet A, De Bacquer D, Valimaa R, Godeau E, Schmid H, Rahav G, et al. Smoking trends among adolescents from 1990 to 2002 in ten European countries and Canada. BMC Public Health 2006;6:280.

18 Mokdad AH, Marks JS, Stroup DF, Gerberding JL. Actual causes of death in the United States, 2000. JAMA 2004;291:1238-45.

19 Lopez AD, Mathers CD, Ezzati M, Jamison DT, Murray C). Global and regional burden of disease and risk factors, 2001: systematic analysis of population health data. Lancet 2006;367:1747-57.

20 Andreasson S, Allebeck P, Romelsjo A. Alcohol and mortality among young men: longitudinal study of Swedish conscripts. $B M$ J 1988;296:1021-5.

21 WHO. Obesity: preventing and managing the global epidemic. Report of a WHO consultation. World Health Organ Tech Rep Ser 2000;894:i-xii,1-253.

22 Cox DR. Regression models and life-tables. J Roy Stat Soc B 1972;34:187-220.

23 Rothman K. Epidemiology: an introduction. New York: Oxford University Press, 2002.

24 Andersson T, Alfredsson L, Kallberg H, Zdravkovic S, Ahlbom A. Calculating measures of biological interaction. Eur J Epidemiol 2005;20:575-9.
25 Bjorge T, Engeland A, Tverdal A, Smith GD. Body mass index in adolescence in relation to cause-specific mortality: a follow-up of 230,000 Norwegian adolescents. Am J Epidemiol 2008;168:30-7.

26 Falkstedt D, Hemmingsson T, Rasmussen F, Lundberg I. Body mass index in late adolescence and its association with coronary heart disease and stroke in middle age among Swedish men. Int J Obes (Lond) 2006;31:777-83.

27 Renehan AG, Tyson M, Egger M, Heller RF, Zwahlen M. Body-mass index and incidence of cancer: a systematic review and meta-analysis of prospective observational studies. Lancet 2008;371:569-78.

28 Neovius M, Rasmussen F. Place of residence and obesity in 1,578,694 young Swedish men between 1969 and 2005. Obesity (Silver Spring) 2008;16:671-6.

29 CAN. Drug habits among military conscripts 2005. Stockholm: CAN 2006. (Report 95.) (In Swedish.) www.can.se/documents/CAN/ Rapporter/rapportserie/CAN-rapportserie-95-monstrandesdrogvanor-2005.pdf.

30 Neovius M, Kark M, Rasmussen F. Association between obesity status in young adulthood and disability pension. Int J Obes (Lond) 2008;32:1319-26.

31 Niedhammer I, Bugel I, Bonenfant S, Goldberg M, Leclerc A. Validity of self-reported weight and height in the French GAZEL cohort. Int J Obes Relat Metab Disord 2000;24:1111-8.

32 Stevens J, Keil JE, Waid LR, Gazes PC. Accuracy of current, 4-year, and 28-year self-reported body weight in an elderly population. Am J Epidemiol 1990;132:1156-63.

33 Nyholm M, Gullberg B, Rastam L, Lindblad U. What is the accurate prevalence of obesity in Sweden in the 21st Century? Methodological experiences from the Skaraborg Project. Obesity (Silver Spring) 2008;16:896-8.

34 Rasmussen F, Eriksson M, Nordquist T. Bias in height and weight reported by Swedish adolescents and relations to body dissatisfaction: the COMPASS study. Eur J Clin Nutr 2007;61:870-6.

35 Bigaard J, Tjonneland A, Thomsen BL, Overvad K, Heitmann BL, Sorensen TI. Waist circumference, BMI, smoking, and mortality in middle-aged men and women. Obes Res 2003;11:895-903.

Accepted: 17 November 2008 